\title{
Consecuencias demográficas de dos epidemias coloniales en las familias de Taximaroa
}

\section{Demographic Consequences of Two Colonial Epidemics for Taximaroa Families}

\author{
José Gustavo González Flores \\ (D) https://orcid.org/0000-0002-4359-0106 \\ Universidad Autónoma de Coahuila, México \\ minerito3@hotmail.com
}

Resumen: En este artículo se analiza la incidencia de las epidemias de matlazáhuatl de 1738-1739 y el tifo de 1813-1814, así como sus consecuencias al interior de las unidades familiares desde el caso de la parroquia de Taximaroa en el obispado de Michoacán. Para lograrlo se recurrió al análisis de las partidas de entierros mediante el método de conteo anónimo (agregativo) y el de reconstrucción de familias. Se concluye que las epidemias de tifo afectaban predominantemente a la población adulta y sus consecuencias fueron más radicales que la viruela o el sarampión, ya que desarticulaban casi por completo a las familias con la muerte del padre, de la madre o de ambos.

Palabras clave: epidemia; tifo; matlazáhuatl; familia; mortalidad; Taximaroa.

Abstract: This article analyzes the matlazáhuatl epidemics of 1738-1739 and the typhus outbreak of 1813-1814, together with their consequences for family units through the case of Taximaroa Parish in the bishopric of Michoacán.

cómo citar: González Flores, J. G. (2020). Consecuencias demográficas de dos epidemias coloniales en las familias de Taximaroa. Secuencia (108), e1769. DoI: https://doi.org/10.18234/secuencia.v0i108.1769 
To achieve this, burial items were analyzed using the anonymous (aggregative) counting method and the family reconstruction. The article concludes that typhus epidemics predominantly affected the adult population and that their consequences were more devastating than those of smallpox or measles, since they almost completely disrupted families as a result of the death of the father, mother or both.

Key words: epidemic; typhus; matlazáhuatl; family; mortality; Taximaroa.

Recibido: 17 de julio de 2019 Aceptado: 23 de octubre de 2019 Publicado: 24 de julio de 2020

\section{INTRODUCCIÓN}

$\mathrm{D}$ urante el siglo XviII se suscitaron varias epidemias que asolaron a la población novohispana, sobre todo a partir del primer tercio de dicho siglo. Si bien se han estudiado a nivel parroquial o regional en distintos casos de la Nueva España, poco se ha dicho en torno a sus efectos a nivel familiar. De los trabajos que han estudiado las epidemias mediante el método de reconstitución de familias, se encuentra el de Paulina Torres (2017b) sobre el caso de Encarnación, en el obispado de Guadalajara, a fines del siglo xviII y principios del xIx. Para la epidemia de tifo de 1814, por ejemplo, esta autora detectó que 243 familias perdieron a más de un miembro (p. 205). Las epidemias afectaban de forma distinta al entorno familiar; había unas que golpeaban más fuerte a la población adulta, como el caso de las de tifo o matlazáhuatl, pero otras como las de viruela y sarampión que se ensañaban más con los niños.

El objetivo principal de este estudio es analizar la incidencia de las epidemias de matlazáhuatl de 1737-1738 y el tifo de 1813-1814, así como sus consecuencias al interior de las unidades familiares desde el caso de la parroquia de Taximaroa. Para este análisis se emplearon las partidas de entierros mediante el método de conteo anónimo ${ }^{1}$ (agregativo) y el de reconstrucción de

${ }^{1}$ En el método agregativo, un evento demográfico se convierte en una variable susceptible de cuantificar. De esta manera se pueden estudiar de manera general las estructuras y diná- 
familias. ${ }^{2}$ Sobre los registros de entierros se deben señalar algunos aspectos relevantes. Los registros hechos por los franciscanos abarcan desde mediados del siglo XVII hasta 1754, cuando la parroquia del estudio se secularizó. Durante este periodo sólo se registró de forma eficiente a los indios adultos y muy mal a castas y españoles. Además, se omitió sistemáticamente el registro de párvulos, fueran indios, españoles o castas. ${ }^{3}$ En este periodo se registró la epidemia del matlazáhuatl de 1737-1739 con las carencias señaladas que se deben tomar en cuenta para hacer el análisis. Luego de 1754, el clero secular asumió la administración de la parroquia y fue más eficiente en el registro de los entierros de todas las edades y calidades.

En el periodo colonial, la parroquia michoacana de San José de Taximaroa tenía su sede en el pueblo de indios de Taximaroa. Se trataba de un asentamiento cuyos orígenes se remontaban al periodo prehispánico donde era parte de la zona fronteriza al oriente del señorío tarasco. Con la llegada de los españoles fue convertido en pueblo de indios cabecera, y en su jurisdicción quedaron varios pueblos de indios sujetos, como San Pedro Jacuaro, San Matías Cataracua, San Lucas Huarirapeo, San Bartolo Cuitareo y San Lorenzo Queréndaro. En la segunda mitad del siglo xvi Taximaroa fue convertida en una de las primeras parroquias del obispado de Michoacán. Estuvo a cargo

mica demográfica de un grupo humano. En este caso con este método se analizó la evolución de la mortalidad de la población de Taximaroa tanto anual como mensual.

${ }^{2}$ Se aplicó el método de reconstitución de familias para ver las consecuencias en el entorno familiar. Tal como Louis Henry (1983) lo sugiere, se ubicó el matrimonio y posteriormente los bautizos de todos los hijos hasta la muerte de uno de los padres, lo cual cierra la reconstrucción de la familia. Sólo se reconstruyeron algunas familias que sirvieron como ejemplo para el momento histórico que se estudia. Tradicionalmente se ha señalado que este método es inaplicable para los casos de las parroquias novohispanas por todos los "escollos metodológicos" tales como la migración, la ausencia de patronímicos de los indios y lo amplio de las parroquias. (Rabell, 1990, p. 9). Sin embargo, ya ha quedado demostrado con muchos estudios la viabilidad del método, por ejemplo, el trabajo de David Carbajal (2008) para el caso de Bolaños, o el de Tomás Dimas Arenas (2014). Para el caso de Michoacán, Oziel Talavera (2007) fue el primero que reconstruyó familias en un pueblo de indios (pp. 269-326) Otro caso, de los casos más exitosos últimamente, es la obra de Paulina Torres Franco (2017a), quien aplica el método de Henry para el caso de la parroquia de Encarnación, en el obispado de Guadalajara.

${ }^{3}$ Esta situación era muy recurrente en el caso de las parroquias con pueblos de indios administradas por franciscanos tal como lo demuestra el caso de Huexotla, por mencionar alguno, donde no se registraban las defunciones de los párvulos (Castillo, Vázquez, Galicia, Navarro, 2017, p. 34). La razón era que los decesos de los infantes en los pueblos de indios no representaban una consecuencia en el sistema de recaudación de tributos, es decir, no eran tributarios y no alteraban las matrículas. Los registros de tributarios servían a las autoridades hispanas para hacer calcular las tasaciones de los tributos que cada pueblo debía hacer a la corona. 
de la orden franciscana hasta mediados del siglo xviII cuando se secularizó. Bajo su jurisdicción quedaron los pueblos de indios señalados, además de un cúmulo de haciendas, ranchos y estancias en los alrededores que se fueron estableciendo durante la segunda mitad del siglo xVI (véase mapa 1).

En cuanto a la calidad de la población, la mayoría la representaron los indios que se encontraban en los pueblos y algunos como trabajadores en las haciendas. A partir de la segunda mitad del siglo xvir se fueron haciendo cada vez más numerosos los individuos de las castas (mestizos, castizos, coyotes y mulatos, entre otros). Pero hacia el primer tercio del siglo xVIII, cuando ocurrió la epidemia de matlazáhuatl, todavía eran muy inferiores demográficamente en comparación con los indios, pero para fines del periodo colonial, cuando sobrevino la epidemia de tifo de 1813-1814, los indios ya no eran mayoría debido a una paulatina mestización que sufrió la parroquia (González, 2016, p. 187-197). Finalmente, los españoles siempre fueron un grupo muy compacto que no creció en todo el transcurso del periodo colonial. Las fuentes coloniales casi siempre dividieron a la población en dos grandes grupos siguiendo un criterio territorial: indios, quienes habitaban en los pueblos, y gente de razón (españoles y castas) que se ubicaban en las haciendas o contiguos al pueblo de Taximaroa.

\section{LAS EPIDEMIAS DEL MATLAZÁHUATL DE 1737-1739 Y LAS FIEBRES DE 1813-1814}

La sobremortalidad por causa de las epidemias fue común desde la llegada de los españoles por el ingreso de nuevas enfermedades. Gracias a la aparición de los registros parroquiales se ha podido profundizar en su estudio mediante la evolución de la mortalidad de la población. En el caso de Taximaroa, los registros de entierros datan de mediados del siglo XVII, pero de manera sistemática se empezaron a realizar hacia el último cuarto de dicho siglo. Esta situación es similar para casi todos los casos del centro y sureste de la Nueva España y algunos casos del septentrión novohispano donde hubo presencia hispana de manera temprana (Cramaussel, 2006, pp. 177-183). Desde que el registro de los entierros se realizó de manera eficiente, se pudieron detectar incrementos de las muertes en algunos años por causa de las distintas epidemias que asolaban a la población. La primera de las grandes sobremortalidades registrada en las partidas de entierros fue la causada por el matlazáhuatl 
Mapa 1. Jurisdicción parroquial de Taximaroa durante el siglo XVIII

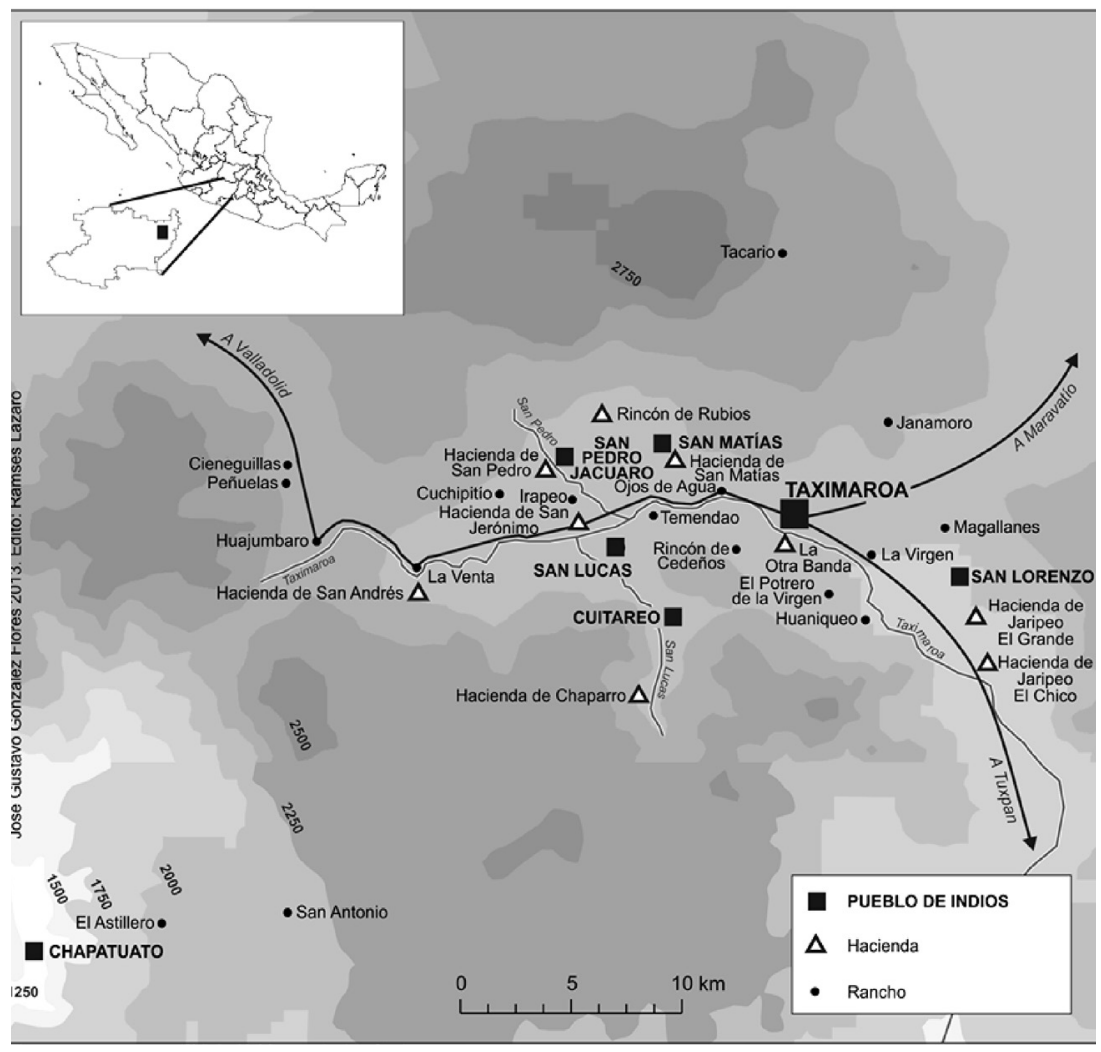

Fuente: González (2016, p. 63).

de 1737-1739. A partir de ella, en la segunda mitad del siglo xviII las epidemias aparecían cada quince o 20 años, aunque en muchos casos aparecieron en años consecutivos. La última del periodo colonial fue la conocida como epidemia de fiebres misteriosas de 1813-1814 (véase gráfica 1).

En este caso se analizan dos de las epidemias más graves que tuvieron mayor incidencia en la población adulta: el matlazáhuatl de 1737-1739 y las fiebres de 1813-1814. Tanto la palabra matlazáhuatl ("red de granos", traducido del náhuatl), como las fiebres están directamente asociadas a los síntomas 


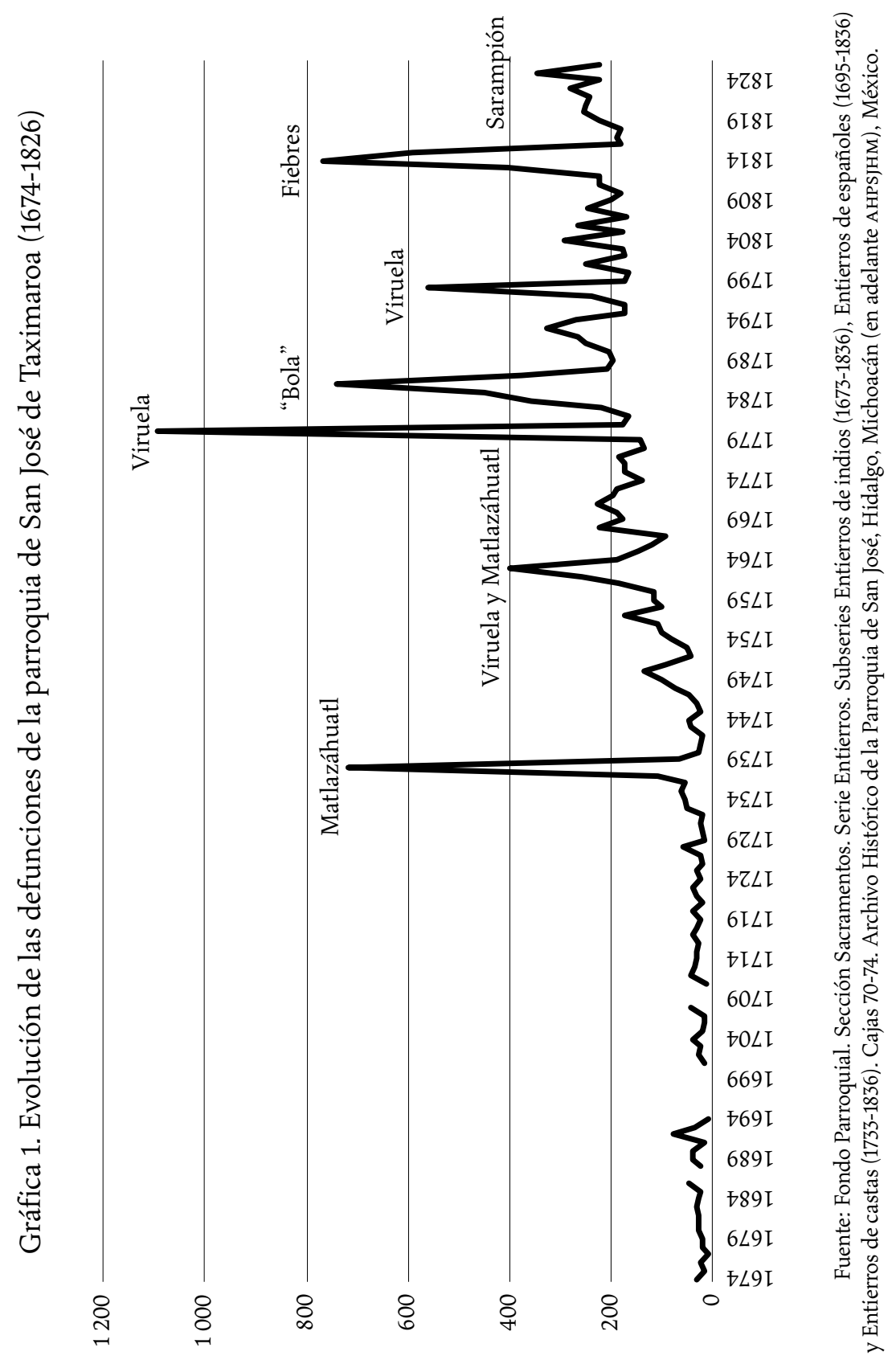


provocados por el tifo, como ya se ha señalado en varios trabajos (Canales, 2006, p. 99; Márquez, 1994, p. 222; Severo, 2013, p. 39; Talavera, 2017, p. 37). Esta palabra nunca fue usada en los registros coloniales novohispanos, aunque se introdujo por primera vez en 1760, en Francia, por el médico François Boissier de Sauvages de Lacroix, quien la utilizó para referirse a unas fiebres que causaba postración (Cramaussel, 2017, p. 87).

Algunos síntomas mencionados por tratados médicos de la época describían los rasgos propios de lo que hoy conocemos como tifo, es decir, "fiebre que ocupa lo superior de la cabeza, agudizándose en las sienes, vómitos, abatimiento del pulso, dificultad al orinar, perturbación de ideas, manchas rojas irregulares. Se trataba de la enfermedad que primitivamente llamaron los mexicanos matlazahuatl" (Montaña, 1817, p. 19-21). Canales (2017), citando tratados de la época, señala además que "les manaba sangre de los oídos y narices, presentaban delirio [eso significa la palabra 'tifo']. Antes de la muerte se presentaban grandes fiebres y una vez muertos, en las autopsias mostraban el hígado muy hinchado, el corazón negro [...] el bazo y el pulmón, negros y semiputrefactos" (p. 13).

La enfermedad conocida como matlazáhuatl o las fiebres se trataba del tifus de tipo exantemático ya que el murino (transmitido por las pulgas de las ratas) es de baja letalidad a diferencia del exantemático que afecta a gran número de población (Canales, 2017, p. 12) Esta era una enfermedad infecciosa provocada por una bacteria denominada Rickettsia prowasekii. Su transmisión es indirecta ya que necesita del piojo que fungía como "vector" o vehículo para transmitir la infección de un individuo a otro, es decir, hombre-piojo-hombre. Las heces de los piojos provocaban la infección cuando era depositada sobre la piel, en ellas se encontraban las bacterias Rickettsia. Cuando las personas se rascaban las picaduras se hacía pequeñas heridas en la piel por donde las bacterias de las heces ingresaban al interior del cuerpo humano. Una vez que el organismo de la persona estaba infectado, se transmitía la enfermedad al piojo cuando este se alimentaba de su sangre. Los huevecillos del piojo infectado o liendres se reproducían rápidamente y se transmitían a otras personas cuando compartían almohadas, ropa, saludos; también, cuando compartían artículos personales o se tocaban las cabezas en los juegos, e incluso por la convivencia cotidiana (Canales, 2017, p. 15). Las relaciones familiares cotidianas eran el vehículo por medio del que se transmitía la enfermedad; por esta razón, una vez infectado un miembro de la familia contagiaba inevitablemente al resto, provocando en algunos casos la muerte de uno o más, como se verá más adelante. 
La epidemia de matlazáhuatl, de 1737, fue una de las epidemias más desoladoras del siglo XVIII, como ya se ha analizado en muchos trabajos, como los de Morin (1973, p. 44) y Calvo (1973, p. 68), pioneros en estudios de historia demográfica en México. Ellos fueron los primeros en señalar la gravedad de la epidemia de matlazáhuatl. Dos de las obras más reconocidas sobre el tema son, por un lado, el de Cuenya (1999) quien estudia las repercusiones de la epidemia en la ciudad de Puebla de los Ángeles, señalando que sus consecuencias se prolongaron durante mucho tiempo en dicho lugar (p. 12). El otro trabajo es el de Molina (2001), que aborda la epidemia a nivel novohispano resaltando que esta epidemia desquició el orden de los pueblos de indios y provocó migraciones multitudinarias (pp. 196, 294). En el caso de Toluca, la cifra de muertos fue tan alta que se multiplicó por quince respecto a los años anteriores (Aguilera, 2013, p. 51).

En 2017 se publicó una obra colectiva que aborda esta epidemia desde los casos de Huexotla, cerca de Puebla (Castillo, 2017, pp. 24-36); de Zinacantepec, en el arzobispado de México (Flores, 2017, pp. 54-64); del valle de Tlacolula, en Oaxaca (Aguilera, 2017, pp. 65-85); y, en algunos casos de la Nueva Vizcaya, en el norte de la Nueva España (Cramaussel, 2017, pp. 86-102). En todos los casos se destacan las funestas consecuencias que no tienen parangón con otras epidemias pasadas ni futuras en muchos de los casos, excepto en los de la Nueva Vizcaya.

En el caso de Taximaroa sólo fue comparable con la de la viruela de 1780 en cuanto a la intensidad y número de muertos (González, 2013, pp. 147177), ya que las demás epidemias (viruela-tifo de 1762-1763, infantil de 1785, la "bola" de 1787, viruela de 1798 y 1815, entre otras) tuvieron una intensidad menor (gráfica 1). De acuerdo con los registros de entierros, la epidemia de matlazáhuatl arribó a Taximaroa procedente del centro del virreinato. Según se ha señalado, esta epidemia se originó en Tacuba, en agosto de 1736, de donde pasó rápidamente a la ciudad de México, desde donde se expandió al oriente del obispado de Michoacán siguiendo los caminos reales. ${ }^{4}$ En Taximaroa la epidemia empezó a multiplicar los decesos en noviembre de 1737, aunque ya se había mencionado desde junio de ese año, en el libro de entierros, con

${ }^{4}$ La ruta México-Valladolid fue trazada desde el siglo xvi y tenía dos vías, una por el norte que seguía la ruta Toluca-Ixtlahuaca-Maravatío-Acámbaro y, la segunda, que recorría Toluca-Zitácuaro-Tuxpan (Castañeda, 2006, pp. 263-266; González, 2013, pp. 147-177). 
la frase "aquí se conoció ser epidemia". ${ }^{5}$ La epidemia se mantuvo elevando el número de decesos durante todo el año de 1738 , en tanto que hasta enero de 1739 la cifra de entierros volvió a la normalidad de los años sin epidemia (véase gráfica 2)

En 1738, año en el que se recrudeció considerablemente la epidemia, el número de muertos registrados ascendió a más de 700 individuos, cifra que multiplicó por doce el promedio de muertos de los dos años previos, sin epidemia. Incluso en una partida de entierros del 1 de noviembre de 1737 se anotó al margen que "aquí pasó la epidemia porque cayeron casi todos aunque no todos fallecieron", es decir, los propios ministros franciscanos tenían la impresión de que toda la población había enfermado. ${ }^{6}$ Debido a que no se registraban infantes no es posible saber la proporción de muerte por edades, sin embargo, por el enorme número de muertes adultas y el tipo de enfermedad (que afectaba primordialmente a los adultos), es probable que estos hayan sido las principales víctimas, tal como ocurre en otros casos novohispanos.

Luego de un periodo aciago de epidemias durante la segunda mitad del siglo xVIII, la última gran epidemia registrada del periodo colonial fue la de 1812-1814. En algunos lugares le denominaron fiebres, fiebres misteriosas o fiebres epidémicas. Desafortunadamente en Taximaroa no se registra la causa de muerte durante todo el periodo colonial, pero se deduce que se trata de la epidemia de fiebres por otros casos estudiados donde la alta mortandad de esos años se debió a esa causa. Tanto esta, como el matlazáhuatl, se ha asociado al tifo debido a los síntomas registrados y a la alta incidencia en la población adulta, aunque en algunos casos los médicos de ese tiempo la asociaron también a otras enfermedades (Talavera, 2017, p. 45). Para el caso del tifo o fiebres de 1813-1814 no se cuenta con noticias cualitativas sobre las impresiones de la epidemia. La mayor parte de los documentos e informes de las autoridades, tanto civiles como eclesiásticas de esos años, se concentraron en describir el movimiento insurgente iniciado por el cura Miguel Hidalgo, que en el oriente del obispado de Michoacán había prendido con mucha fuerza. En la zona oriente del obispado de Michoacán se movilizaron tropas realistas a cargo de diversos generales como Diego García Conde, Ciriaco del Llano,

${ }^{5}$ Fondo Parroquial. Sección Sacramentos. Serie Entierros. Subserie Libro de entierros de indios 3. АнРsјнм, México.

${ }^{6}$ Fondo Parroquial. Sección Sacramentos. Serie Entierros. Subserie Libro de entierros de indios 3. Анрsјнм, México. 


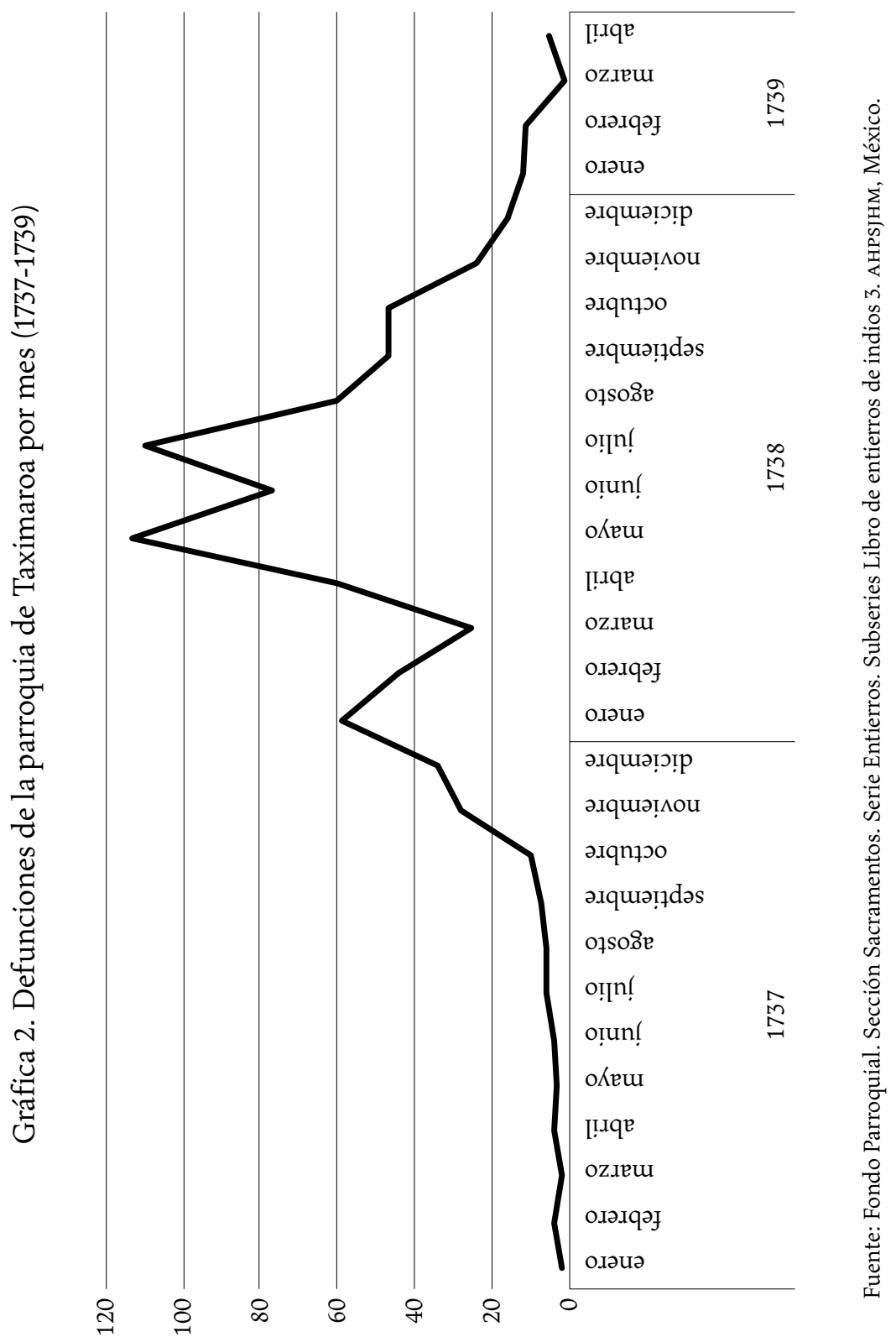


Agustín de Iturbide, Joaquín Castillo Bustamante y Manuel de la Concha, liderados por Félix María Calleja, en contra de los hermanos López Rayón, principalmente (Pérez, 1986, p. 183; 1990, pp. 152-153).

Según se ha dicho, esta epidemia de fiebres o tifo se originó en la batalla del "Sitio de Cuautla", donde el insurgente José María Morelos había peleado con las fuerzas del general Calleja, en 1812. El hacinamiento y la falta de higiene durante el sitio fueron los elementos que propiciaron su propagación entre los sitiados y, al romperse, la epidemia se difundió en el resto de la población del virreinato (Ortiz, 1994, p. 96).

A Taximaroa llegó la epidemia en el mes de septiembre de 1813, cuando comenzó a incrementar el número de decesos y menguó hasta septiembre de 1814. Entre 1813 y 1814 el número de muertos alcanzó la cifra de 1173; 404 fallecieron en 1813 y 769 en 1814 . Durante este último año el número de decesos fue 3.4 veces mayor que el de años pasados, sin epidemia. Talavera señala para Uruapan y Valladolid, en el obispado de Michoacán, que la epidemia de 1814 fue una crisis menor, no tan fuerte como la de 1780 y 1786 que, por lo menos en el caso de Valladolid, habían sido más graves (Talavera, 2013, p. 124). En el occidente y norte novohispanos la intensidad de esta epidemia fue mucho más grave que en el centro del virreinato. En las parroquias de Jalostotitlán y Santa María de los Lagos, los muertos se multiplicaron por nueve (Becerra, 2017, p. 178), mientras que, en Parral, San Bartolomé (Cramaussel, 2017, p. 94) y Parras (González, 2017 p. 221), en el reino de Nueva Vizcaya los decesos se multiplicaron por seis, tres y cinco, respectivamente.

Por ser una epidemia de tifo tuvo mayor impacto en la población adulta, matando a poco más de dos terceras partes del total de los fallecidos entre 1813 y 1814, mientras que en años anteriores, sin epidemias, las muertes por edad eran más o menos proporcionales entre adultos y párvulos (véanse gráfica 3 y cuadro 1). Esto mismo se constata para los casos mencionados (Severo, 2013, p. 68; Talavera, 2013, p. 143).

En ese periodo de epidemia, la guerra insurgente recrudeció aún más la situación. El incesante traslado de personas, entre tropas y gente que huía de la guerra, quedó reflejado en el libro de entierros de Taximaroa, donde se registraron, entre 1813 y 1814, por lo menos 29 adultos cuya procedencia familiar se desconocía, es decir, no hubo ni siquiera quién diera noticia de sus familiares. De este grupo incluso cuatro de ellos fueron consignados como forasteros, pero posiblemente los demás lo eran también. Por razones obvias, la mayoría de estos muertos fueron enterrados de limosna ya que no hubo 


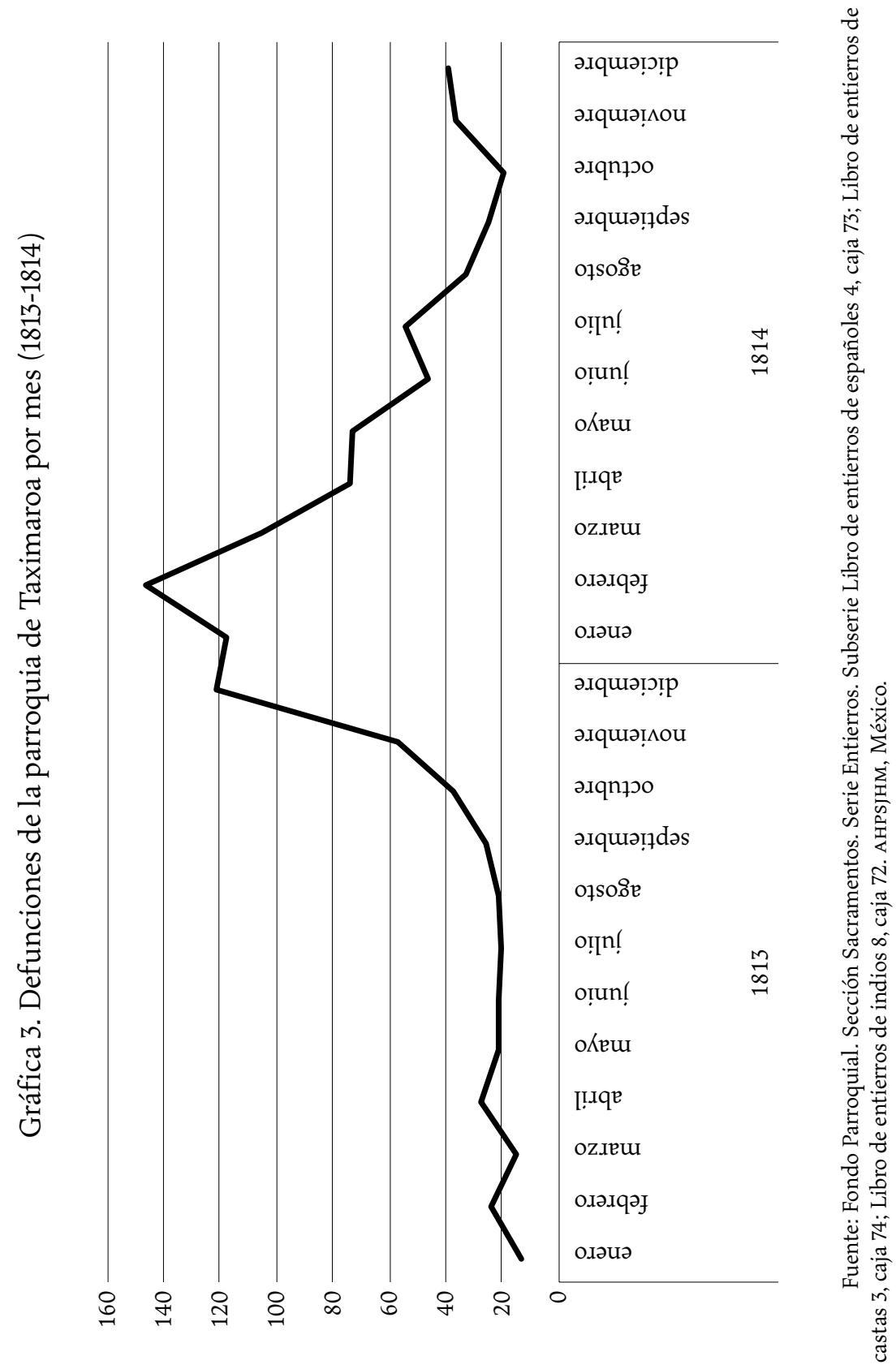


Cuadro 1. Defunciones de Taximaroa por edad (1811-1814)

Año Adultos Párvulos Porcentaje Adultos Porcentaje Párvulos

$\begin{array}{lllll}1811 & 125 & 105 & 54.3 & 45.7 \\ 1812 & 122 & 105 & 53.7 & 46.3 \\ 1813 & 263 & 141 & 65.10 & 34.90 \\ 1814 & 492 & 277 & 63.98 & 36.02\end{array}$

Fuente: Fondo Parroquial. Sección Sacramentos. Serie Entierros. Subserie Libro de entierros de españoles 4, caja 73; Libro de entierros de castas 3, caja 74; Libro de entierros de indios 8, caja 72. АнРsјнм, México.

quien pagara sus pompas fúnebres. ${ }^{7}$ Aunque no se registra la causa de muerte, es muy probable que la mayoría de estos decesos fueran provocados por el tifo, ya que ocurrieron en los últimos meses de 1813 y en 1814, tiempo en el que se recrudeció la epidemia. Cabe señalar que sólo en dos casos se consignó la muerte como violenta.

Las epidemias de matlazáhuatl de 1737-1738 y fiebres de 1813-1814 fueron de las que más muertos dejaron a su paso por Taximaroa. Sus principales víctimas estuvieron entre la población adulta. Las cifras generales de muertos ponen en relevancia la importancia cuantitativa de lo funesto que podían llegar a ser las epidemias, pero si ampliamos el nivel de análisis al contexto familiar, se profundiza aún más en el impacto de las sobremortalidades y sus consecuencias sociales. Si bien la muerte era un fenómeno recurrente, el impacto de las epidemias al interior de las familias muestra un panorama que nos permite acercarnos incluso a otras latitudes historiográficas, como la historia de la familia ante la muerte. Esto se verá a continuación.

${ }^{7}$ Fondo Parroquial. Sección Sacramentos. Serie Entierros. Subserie Libro de entierros de españoles 4, caja 73; Libro de entierros de castas 3, caja 74; Libro de entierros de indios 8, caja 72. АнРзјнм, México. 


\section{EPIDEMIA Y MUERTE EN EL INTERIOR DE LAS FAMILIAS}

Las epidemias de viruela o sarampión, cuyas víctimas eran principalmente los niños, dejaban una estela de muerte que mermaba seriamente a las familias, pero una epidemia que cobraba la vida principalmente de los adultos, como las de matlazáhuatl o tifo, tenía serias repercusiones a nivel familiar porque la trastornaba desde sus estructuras. No era lo mismo que durante una epidemia muriera uno o varios hijos a que lo hiciera el padre, la madre o ambos. La muerte de los padres podía reducir a los demás miembros de la familia a la mendicidad o fomentar las segundas nupcias, tal como se verá a continuación.

Para el caso del matlazáhuatl de 1737, Cayetano Cabrera Contreras, presbítero de la época, registró, en su conocida obra Escudo de Armas, las consecuencias funestas de dicha epidemia en el entorno familiar en la ciudad de México. En algunas desoladoras descripciones estaban implicadas familias completas que perecían víctimas de la enfermedad, como en las que "caía muerto el marido, moribunda sobre él su consorte y ambos cadáveres eran el lecho en el que yacían enfermos los hijos" (Cabrera, 1981, p. 48). Obviamente el autor daba énfasis a estos escenarios para justificar la gravedad de la epidemia que, según Escudo de Armas, fue resuelta con la entronización de la Virgen de Guadalupe en la ciudad.

Desafortunadamente para el caso de Taximaroa no se cuenta para este periodo con documentos cualitativos que den noticia sobre la situación familiar en tiempos de esta peste que inició en 1737. Ni siquiera existe un padrón que ofrezca un panorama sobre las características de los hogares y las familias en la parroquia de Taximaroa alrededor de los años de la epidemia. Sin embargo, los propios franciscanos quedaron tan impactados de la letalidad de la epidemia que, en el mismo libro de entierros, señalaron la llegada de esta, en junio de 1737, y llevaron un conteo pormenorizado del número de muertos, desde entonces hasta finales de 1738 . También hicieron algunas anotaciones al margen de las partidas de entierro en la que muestran el panorama desolador a nivel familiar.

Los franciscanos plasmaban al margen de las partidas, sin obligación de hacerlo, anotaciones parecidas a las referidas en la obra Escudo de Armas. En el libro de entierros los frailes alarmados plasmaban cómo la epidemia cobraba la vida de parejas y familias enteras. En varias ocasiones los ministros 
añadieron en las partidas de entierros frases como "recién muerto el esposo", "después de que murió su esposa murió él inmediatamente", "el marido se está muriendo", "estos esposos murieron al mismo tiempo" o "hija de la recién muerta viuda de la Cruz". ${ }^{8}$

Estas expresiones nacían, sin duda, del impacto que la morbilidad y mortalidad estaban causando al interior de las familias y de la frecuencia con la que varios miembros de la familia perecían por la peste. Debido a que no se cuenta con un registro eficiente de párvulos, castas y españoles de 1737 a 1739, para analizar las consecuencias de la epidemia en las familias sólo se incluyen los registros de entierro de las parejas de indios que fueron ubicados por sus nombres. Por ejemplo, en agosto, cuando la epidemia recién llegaba a la jurisdicción parroquial, murió Juan Simón, indio de Taximaroa que probablemente contagió a su esposa y cuyo trágico fin llegó en enero del año siguiente, es decir, cuatro meses después de la muerte de su marido y en plena expansión de la epidemia. Peor suerte corrió María Petrona, quien vio morir a su marido, Pascual Fabián, en mayo de 1738. Ella murió sólo tres meses después, en agosto.

Hubo, sin embargo, muertes de consortes con un mes de diferencia o incluso días, como el caso de Francisco de la Cruz, indio del pueblo de Cuitareo que murió el 31 de marzo de 1738 y, menos de un mes después, el 26 de abril falleció su consorte, María Isabel. Todavía más súbita fue la muerte de María Juana y su esposo Andrés Martín, indios de San Lorenzo, siendo la muerte de la primera el 11 de junio de 1738 y sólo una semana después, el 18 de junio la del esposo. La epidemia no ofreció tregua todo ese año, lo que motivó que hubiera partidas de entierro como la de Antonia María, en donde se expresaba que el esposo se estaba muriendo. Dicho diagnóstico no podía ser más acertado, ya que a tan sólo diez días de la muerte de esta, el marido también expiró. Pero lo que alarmaba aún más en tiempo de la epidemia era la muerte casi súbita de ambos consortes, como la de Juan Matías y María Pascuala, quienes murieron quizá con horas de diferencia, pero los dos fueron registrados el 21 de julio de 1738 . Como este caso quedaron consignados en el

${ }^{8}$ Fondo Parroquial. Sección Sacramentos. Serie Entierros. Subseries Entierros de indios 3. Aнрлјнм, México. Desgraciadamente para las siguientes epidemias, el clero secular (llegado en 1754) no tuvo la misma "curiosidad" en anotar datos cualitativos que reportaran la gravedad e incidencia de las epidemias, ya que sólo se dedicaron a asentar las partidas de entierros sin distinguir los momentos de sobremortalidad, tal como lo hicieron los franciscanos durante la epidemia del matlazáhuatl de 1737-1738. 
libro de entierros de indios otros más que muestran las consecuencias de la epidemia al interior de las familias, esto sin contar con las muertes de los hijos que no fueron registrados.

El impacto de la epidemia a nivel familiar entre los indios fue evidente, en tanto que de los 638 decesos de adultos casados en los que se consigna el nombre de la pareja, poco más de un tercio (226) corresponde a ambos consortes, es decir, 113 parejas. ${ }^{9}$ A nivel social esto significó que 113 familias quedaron sin padre ni madre durante el periodo de la epidemia (de junio de 1737 a diciembre de 1738). Aunque el fenómeno de la muerte era común, ya fuera por la alta mortalidad infantil o por el descuido e inoperancia de las medidas de prevención de las enfermedades en la población adulta, era raro que en un periodo de un año o menos murieran ambos padres en una familia. Por ejemplo, entre 1734 y 1736 solamente murieron dos parejas con un rango de tiempo considerable entre un consorte y el otro. ${ }^{10}$

Debido a las deficiencias de la fuente, ya señaladas, la muerte de ambos padres en una familia no es sino un indicador que muestra la letalidad de la epidemia ante la imposibilidad de conocer sus repercusiones en los demás miembros de una unidad familiar. Mas si en una familia morían ambos padres fue porque la epidemia cundió al interior del seno familiar o de los hogares y se llevó a la tumba seguramente a uno o varios hijos de cierta edad. No se debe olvidar que el padecimiento conocido como matlazáhuatl era una especie de tifo exantemático que se acentuó más en la población adulta.

La muerte de ambos padres traía una segura desintegración familiar, más aún si se trataba de familias nucleares como seguramente ocurrió en algunos casos que por ahora no es posible precisar. Ello por la ausencia de padrones en donde se especifique el tipo de hogares que prevalecía en los asentamientos de la jurisdicción parroquial. Esto obligaría a los huérfanos a asumir nuevas circunstancias para su subsistencia. La mayoría quizá fueron recogidos por parientes cercanos o padrinos, como se ha comprobado para otros casos como Yucatán (Malvido y Peniche, 2013, p. 138). Esto fomentó las familias extendidas donde los padres y sus hijos tuvieron que convivir en el mismo

${ }^{9}$ El total de muertos indios adultos, de junio de 1737 a diciembre de 1738 , fue de 777 . De esta cifra 100 fueron solteros o doncellas y en 38 casos no se especificó el nombre de la pareja por tratarse de "viudas viejas" o muertos foráneos. El número de decesos que incluyó a esposo y esposa de un mismo matrimonio fue de 226. Véase Fondo Parroquial. Sección Sacramentos. Serie Entierros. Subseries Libro de entierros de indios 3. Анрsјнм, México.

${ }^{10}$ De 1734 a 1736 murieron 115 adultos, sólo cuatro de ellos eran esposos, es decir, dos parejas. 
hogar con parientes o "arrimados" que se habían quedado huérfanos durante la epidemia. En el peor de los casos, algunos de estos huérfanos tendrían que haberse incorporado al campo laboral en condiciones desventajosas.

En cuanto a la epidemia de fiebres o tifo de 1813-1814 -a pesar de no haber sido anunciada debidamente porque la guerra insurgente acaparaba la atención de las autoridades- empezó a notarse en Taximaroa con el aumento sustantivo de los muertos en los libros de entierros de la parroquia, desde septiembre de 1813 y durante 1814. Gracias al método nominativo se pudo identificar la muerte al interior de las familias, tal como se hizo en el caso de la de matlazáhuatl de 1737-1738. No obstante, gracias al buen registro del clero secular, donde se asentó de manera sistemática a los infantes, las castas y los españoles fue posible, incluso, reconstruir familias completas y el impacto de la epidemia de fiebres o tifo de estos años. ${ }^{11}$

El 12 de noviembre de 1792 contrajeron nupcias Agustín Antonio y María Juliana, indios del pueblo de Cuitareo. Agustín Antonio había perdido a su primera esposa, María Simona, cuatro años atrás. María Juliana también era viuda desde hacía once años. Dos años después de la boda, en mayo de 1794, estos esposos trajeron al mundo a su primera hija, María de la Luz y, el 26 de octubre de 1796, nació José Lucas. El primer varón de esta familia no vivió más de un año; murió el 30 de octubre del año siguiente. Fue hasta 1800 cuando nació otro varón que fue llamado José Hipólito. En los años siguientes ya no hubo más nacimientos o decesos registrados de esta familia hasta que, el 30 de abril de 1814, justo en medio de la epidemia de tifo murió el padre, Agustín Antonio.

Hubo muchos casos en los que más de un miembro de la familia moría durante la epidemia, como la familia de los indios Antonio Domingo y María Gregoria, oriundos del pueblo sujeto de San Lorenzo. Esta pareja se casó el 22 de diciembre de 1805. Antonio Domingo lo hacía en segundas nupcias debido a que un año y medio atrás había enviudado por la muerte de su primera esposa María Ignacia. Tan sólo seis meses después de la boda nació la primera

${ }^{11}$ Los datos para la reconstrucción de familias fueron obtenidos de: Fondo Parroquial. Sección Sacramentos. Serie Bautismos. Subserie Libro de bautismos de indios núms. 1-17, españoles núms. 1-5, y de castas núms. 1-8, cajas 1-12. Fondo Parroquial. Sección Sacramentos. Serie Matrimonios. Subserie Libro de matrimonios de indios núms. 1-8, de españoles núms. 1-6, y de castas núms. 1-3, cajas 19-23. Fondo Parroquial. Sección Sacramentos. Serie Bautismos. Subserie Libro de entierros de indios núms. 1-8, de españoles núms. 1-5, y de castas núm. 1-3, cajas 70-74. АнрSјнм. 
hija de esta pareja, la llamaron María Rita. Era evidente que la esposa iba embarazada a la hora del matrimonio. Cabe señalar que las relaciones sexuales prematrimoniales no eran algo extraordinario sobre todo en las comunidades indígenas ya que bastaba con la palabra de matrimonio para que el pretenso pudiera acceder a tener intimidad con la mujer (Aguilera, 2011, pp. 73-75). En enero de 1808 nació su segunda hija que fue bautizada como María Antonia Margarita, pero en mayo de ese mismo año murió la primogénita, María Rita. El 1 de noviembre de 1811 nació el primer varón, José Cecilio de los Santos. En diciembre de 1813, el padre de la familia, Antonio Domingo, enfermó y murió por la epidemia, dejando dos huérfanos y viuda. Un mes después, en enero de 1814 el niño José Cecilio de los Santos también falleció, aunque debido al tipo de epidemia, que afectaba sólo a los adultos, no se sabe si el menor murió por el tifo u otra enfermedad. Ni siquiera habían pasado diez años de su boda y María Gregoria ya había perdido a su marido y dos hijos, engrosando la lista de las viudas, que para entonces eran consideradas como desgraciadas, como se verá más adelante.

El caso del matrimonio de Isidro de la Cruz y María de la Luz, indios de San Lucas, ilustra lo visto ya en el caso del matlazáhuatl cuando ambos padres perecían durante una epidemia. Esta pareja se había casado el 16 de agosto de 1773; ambos eran viudos cuando llegaron al altar. Isidro tenía dos años en ese estado y María de la Luz apenas cinco meses. Como se verá más adelante, las segundas nupcias eran muy comunes y se acentuaban en los periodos posteriores a las epidemias. Un año después de la boda nació María Josefa. Aunque no se registra el bautizo de su segundo hijo, llamado José Ciriaco, este nació probablemente entre fines de 1775 y 1784, ya que falleció en el año de 1785 durante una epidemia infantil (González, 2016, pp. 122-128). En noviembre de 1789 nació María Luciana y, dos años después, María Rafaela. Muchos años y epidemias pasaron sin que se registrara la muerte de algún miembro de esta familia hasta que, en diciembre de 1814, justo al final de la epidemia de tifo, Isidro de la Cruz y su mujer murieron con horas de diferencia, ya que fueron registrados el mismo día y fueron enterrados de limosna.

Los periodos de epidemia no distinguían calidad ni posición económica. El 20 de mayo de 1778 se casaba el acaudalado español don Diego Tomás Gutiérrez con doña María Laureana Pozo, hija de una distinguida familia de Acámbaro. Curiosamente, poco menos de ocho meses después, nacía la primera hija a quien llamaron María Tiburcia. Entre esta fecha y 1799 nacieron otros cinco hijos, tres varones y dos mujeres. Ninguno de ellos murió en edad 
temprana ya que no se registra ningún deceso. Sin embargo, llegada la epidemia de tifo cobró la vida de la madre de la familia, en septiembre de 1813 y, poco menos de un año después, en agosto de 1814, su esposo, don Diego Tomás Gutiérrez, también perecía como una víctima más.

Hubo casos todavía más alarmantes en los que la epidemia se ensañó al interior de las familias. José Doroteo y María de la Luz contrajeron nupcias el 11 de mayo de 1797. Ambos eran indios trabajadores de la hacienda de San Andrés y en algunas temporadas laboraban para la hacienda de La Teja. El 5 de noviembre de 1798 fue llevada al bautizo su primera hija, nombrándola Antonia de los Santos. En diciembre de 1800 nació José Guadalupe y, en noviembre de 1802, Juana María Francisca, quien falleció tan sólo siete días después. Posiblemente, entre 1804 y 1813, nació otra hija llamada María Cecilia, aunque no se halló su registro de bautizo, pero sí el de su muerte, como se verá. Muchos años pasaron sin que se registrara ninguna muerte en la familia hasta que, en diciembre de 1813, cuando la epidemia de tifo arreciaba, se llevó a la tumba a tres miembros de la misma. El 9 de diciembre pereció José Guadalupe, al día siguiente su padre, José Doroteo y, el 22 del mismo mes, su madre, María de la Luz. Tres meses después hubo otro deceso, María Cecilia, la hija más pequeña. En esta familia, la epidemia sólo perdonó a la hija mayor, Antonia de los Santos.

Una situación todavía peor padeció la familia del matrimonio integrado por José Paulino y María Antonia, indios gañanes del rancho de la Virgen. El 7 de septiembre de 1796 esta pareja se casó y durante los diez años posteriores tuvieron cinco hijos. En 1798 nació María Catalina, dos años después vio la luz María Mauricia Isidra. En 1802 y 1804 nacieron María Concepción Gil y Juana María Feliciana, respectivamente. Finalmente, María Timotea nació en agosto de 1806, pero tan sólo dos meses después, el 5 de octubre, ya había muerto. Posiblemente entre 1807 y 1813 nació María Estefanía, aunque no se halló su registro de bautizo, pero sí el de su entierro. A la llegada de la epidemia de tifo, prácticamente toda la familia enfermó y, para el mes de febrero de 1814, el espectáculo fue siniestro. Uno a uno fueron pereciendo todos los integrantes de la familia. El 5 de febrero la hermana mayor, María Catalina, y la menor, María Estefanía, murieron quizá con horas de diferencia. Tres días después, su madre María Antonia había expirado. Ni una semana pasó cuando, el 12 de febrero, llegó el turno de José Paulino, el padre de familia y, dos días después, pereció María Isidra, la última de la familia que quedaba con vida. 
Así como estos casos, podrían describirse muchos más en los que la epidemia causó estragos dentro de las familias de la parroquia de Taximaroa. En términos generales, de los 1,173 decesos en los años de 1813 y 1814, más de un tercio (430) eran familiares directos, es decir, esposos, padres e hijos o hermanos. De entre ellos, en 310 casos perecieron dos miembros de una misma familia y, en los otros 120 casos, fueron más de dos familiares los fallecidos durante la epidemia. Cabe señalar que, del total de las víctimas adultas por la epidemia, 575 eran personas casadas. De ellos hubo 44 parejas de esposos (15\% del total de los adultos casados) que perdieron la vida durante la epidemia, lo que representó literalmente la desintegración de esas familias. Para la parroquia neogallega de Encarnación, también se encontró que las epidemias alteraban la configuración de la familia, pues para las epidemias de $1780,1786-1787$ y $1798,28 \%$ de los decesos ocurrieron entre familiares (Torres, 2013, p. 231).

Las epidemias alteraban de manera irremediable la configuración de las familias, más aún cuando morían uno o los dos padres. En el primer caso la pareja que quedaba viuda reingresaba al mercado matrimonial susceptible de contraer segundas nupcias. Entonces, otras de las consecuencias de las epidemias en las familias fueron las segundas y ulteriores nupcias, fenómeno muy común en los periodos posteriores a las sobremortalidades. Esto podía considerarse como una estrategia de supervivencia familiar del padre o madre de familia que había superado la epidemia. Asimismo, era un mecanismo que coadyuvaba en la recuperación demográfica luego de las crisis también de tipo demográficas.

\section{VIUDOS, VIUDAS Y SEGUNDAS NUPCIAS DESPUÉS DE LAS EPIDEMIAS DE 1737-1738 Y 1813-1814}

En las poblaciones del antiguo régimen era muy común que los viudos o las viudas, luego de la muerte de su pareja, buscaran casarse nuevamente. Varios casos estudiados para Nueva España así lo sancionan. En San Luis de la Paz, $80 \%$ de los viudos volvieron a casarse, a menos de un año de la muerte de su pareja, durante el matlazáhuatl de 1763. En Tula ocurrió algo similar con la epidemia de 1739 (Rabell, 1990, p. 24). Los casos de los centros mineros de Bolaños (Carbajal, 2008, p. 141) y Sombrerete (Arenas, 2014, p. 278), al occidente y norte de Nueva España, confirman la premura con la que los viudos busca- 
ban casarse luego de las crisis demográficas. De la misma manera, durante los últimos 40 años del periodo colonial, en la villa de la Encarnación, en Nueva Galicia, los matrimonios aumentaban considerablemente luego de las epidemias con incidencia en la población adulta, gracias a las segundas nupcias (Torres, 2013, p. 236) (véase gráfica 4).

En Taximaroa, la epidemia de matlazáhuatl de 1737-1739, además del crecido número de muertos, había dejado un saldo sobresaliente de indios e indias adultos en disponibilidad de casarse, es decir, debido a la enorme cantidad de personas que enviudaron ante la muerte de su pareja, había una especie de sobrepoblación en el mercado nupcial hacia 1739. En Taximaroa, alrededor de 400 personas perdieron a su pareja en el periodo de la epidemia y estaban con la posibilidad de volver a casarse, junto con los solteros y doncellas que habitualmente lo hacían año con año. Esto sin contar que todavía en los primeros meses de dicho año, debido a las últimas secuelas de la epidemia, murieron 21 adultos de los que siete eran viudos que habían perdido a su consorte el año anterior $y$, los otros catorce, integraban siete matrimonios que posiblemente habían contraído la enfermedad, pero murieron hasta $1739 .^{12}$

Regularmente, el número de matrimonios de los indios oscilaba alrededor de las 55 celebraciones anuales, pero en 1739, luego de que la epidemia de matlazáhuatl había pasado, entre los viudos que dejó la epidemia y los solteros que cotidianamente se casaban, provocaron un crecimiento espectacular más allá de los 120 enlaces nupciales. Esta cifra duplicó la de los matrimonios en años sin epidemia. De los 240 consortes implicados en los matrimonios señalados, 148 eran viudos, es decir, más de dos tercios (68\%). Este crecido número de nupcias se realizó en su mayoría en los meses de febrero y julio, periodos en los que por lo regular había más celebraciones matrimoniales en años sin epidemia.

Otro tanto pasó con la epidemia de fiebres o tifo de 1813-1814. De los 755 adultos que murieron entre 1813 y 1814,487 quedaron viudos, ${ }^{13}$ convirtiéndose en potenciales candidatos al matrimonio. Poco antes de la epidemia, el pro-

${ }^{12}$ Fondo Parroquial. Sección Sacramentos. Serie Entierros. Subserie Libro de entierros de indios 3. Анрsјнм, México.

${ }^{13}$ De los 1173 muertos, 755 eran adultos. De ellos 180 eran solteros y 575 casados. Si descontamos a las 44 parejas en las que ambos murieron, el total de personas que enviudaron fueron 487. Véase Fondo Parroquial. Sección Sacramentos. Serie Entierros. Subserie Libro de entierros de españoles 4, caja 73; Libro de entierros de castas 3, caja 74; Libro de entierros de indios 8, caja 72. Анрsјнм, México. 


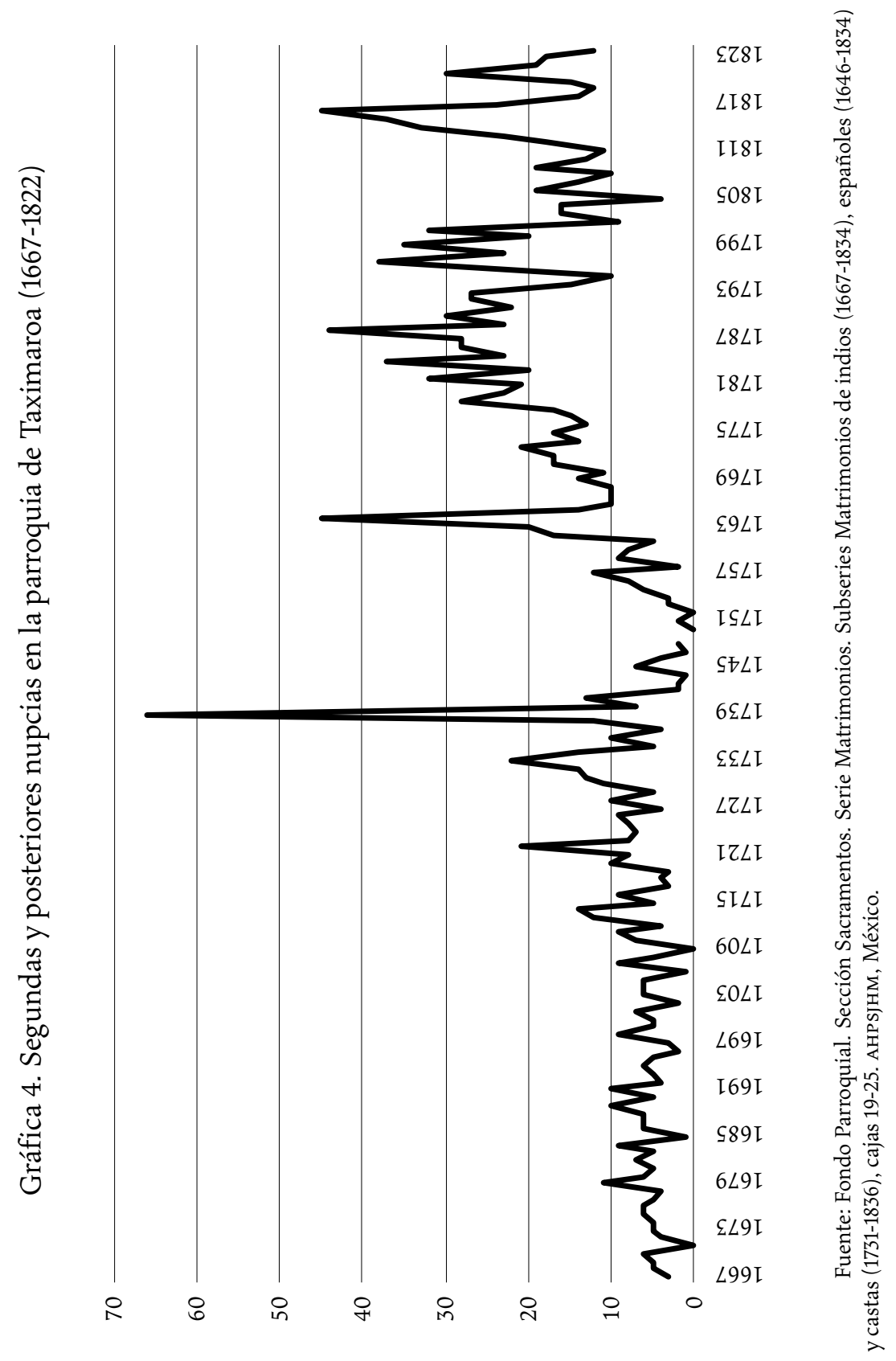


medio de matrimonios anuales era de 75 pero, desde 1814, la cifra de matrimonios aumentó alcanzando los 114 enlaces. En el año de 1815 se registró un descenso en el número de los matrimonios, pero en 1816 la cifra nuevamente se disparó alcanzando las 123 uniones matrimoniales. A diferencia de los viudos que dejó el matlazáhuatl de 1737-1738, en el tifo de 1813-1814, los que perdieron a sus parejas no acudieron en masa en el año siguiente a contraer matrimonio, sino que lo hicieron de manera menos vehemente. Se debe tomar en cuenta que en 1815 una epidemia de viruela volvió a golpear a la población y eso posiblemente ralentizó o postergó las segundas nupcias.

El caso de Florencio Blas, indio de San Pedro, ilustra el proceder de gran parte de los que quedaron viudos durante la epidemia de matlazáhuatl de 1737-1738 que buscaban volver a casarse con celeridad. Florencio Blas se casó con María Candelaria, una india también de San Pedro, el 9 de agosto de 1726. Con esta mujer procreó por lo menos dos hijos: Marcelo, bautizado el 14 de febrero de 1730, y Lorenza, el 24 de agosto de 1732. Durante la epidemia de matlazáhuatl, el 17 de mayo de 1738 murió su mujer. Tan sólo ocho meses después, el 15 de febrero de 1739, Florencio Blas volvió a casarse, ahora con Dominga María, una viuda que también había perdido a su marido durante la epidemia, en abril de 1738. De este nuevo matrimonio nació Blasa Candelaria, a principios de febrero de 1750 . Florencio Blas volvió a enviudar, en diciembre de 1762, por la muerte de Dominga María, posiblemente durante la epidemia de tifo de ese año (González, 2016, p. 115-119).

En la misma situación se halló Gaspar Sureque, indio de Taximaroa. Aunque no se localizó la partida de matrimonio, posiblemente se casó a fines de la década de 1720 con María de la Cruz, con la que tuvo cinco hijos entre 1730 y 1736 . El 14 de enero de 1738 perdió a su esposa, justamente cuando la epidemia causaba grandes estragos en la población. Con cinco hijos huérfanos, Gaspar Sureque empezó a buscarles una madre lo más pronto posible. A su vez, Paula Manuela, india también de Taximaroa, se había casado con Antonio Flores el 25 de noviembre de 1733. Hasta antes de la epidemia había tenido dos hijos, pero en julio de 1738 , la peste acabó con su marido dejándola viuda y con dos hijos huérfanos. Tanto Gaspar Sureque como Paula Manuela, viudos por causa de la epidemia de matlazáhuatl, vieron necesario buscar pareja para resguardo de sus hijos. En marzo de 1739 decidieron casarse, Gaspar tenía poco más de un año de haber enviudado y Paula Manuela apenas siete meses. Esta nueva pareja tuvo otros nueve hijos entre los años de 1740 a 1758. $\mathrm{Al}$ año siguiente, Gaspar Sureque volvió a quedar viudo con la muerte de su 
segunda esposa, Paula Manuela, el 10 de mayo de 1759. Este prolijo indio habría procreado 14 hijos, de 1728 a 1758, con sus dos esposas.

Para la epidemia de fiebres o tifo de 1813-1814, también hay algunos casos que muestran la importancia de que las segundas nupcias debían ser lo más pronto posible. Por ejemplo, José María Luis perdió a su esposa durante los primeros meses de la epidemia, en noviembre de 1813, pero para abril de 1815, se casó nuevamente, esta vez con María Magdalena. Caso similar fue el de Felipe Hernández quien enviudó en enero de 1814 y se casó en segundas nupcias un año y diez meses después con Juana María, es decir, en marzo de 1816. De la misma manera, José Perfecto Campos quedó viudo el 24 de octubre de 1813, cuando la epidemia comenzaba a prender en la parroquia de Taximaroa. En un año y cuatro meses se casó con María Margarita López. Una de las segundas nupcias al menor tiempo, con respecto de la muerte de la primera consorte, la tenemos en el caso de José Tomás Merlos, quien había enviudado de María de la Cruz Díaz, el 24 de abril de 1814. El viudo ni siquiera esperó a que terminara ese año pues en diciembre, es decir, siete meses después de haber enviudado, contrajo nupcias nuevamente, ahora con María Josefa Campos.

En muchos casos la premura era por la necesidad de buscar madres o padres sustitutos para los huérfanos como ya se vio en algunos casos de la epidemia de matlazáhuatl, de 1737-1739. José Mariano Cabrón, español del rancho de la Longaniza dentro del valle de Jacuaro, contrajo nupcias con la española María Guadalupe Gutiérrez, el 26 de noviembre de 1794, quien le dio cuatro hijos entre 1804 y 1814 . Cuando la epidemia menguaba sus efectos, el 10 de noviembre de 1814, la mujer falleció de la debilidad provocada por el tifo y el parto de su último hijo, quien había nacido un día antes. Los cuatro hijos huérfanos encontraron una madre sustituta en María de los Ángeles Trujillo, con quien Mariano Cabrón se casó el 18 de agosto de 1817, a sólo dos años de haber enviudado. Esta mujer también era viuda de Longinos Cañas, con quien se había casado en febrero de 1803 y había procreado tres hijos, dos de los cuales habían muerto antes de noviembre de 1814.

En síntesis, volverse a casar poco tiempo después de haber enviudado durante las epidemias de matlazáhuatl de 1737-1738 y tifo de 1813-1814 muestra la importancia del estar casado como estado ideal para la sociedad colonial de Taximaroa, donde la viudez se consideraba como un estado transitorio. Las razones de este afán por parte de los viudos para matrimoniarse sin dejar pasar mucho tiempo, obedecía probablemente a dos razones: la primera era 
porque tanto el derecho canónico ${ }^{14}$ como los decretos episcopales, ${ }^{15}$ inspirados en la carta de San Pablo a Timoteo, en el Nuevo Testamento de la Biblia (2005), señalaban que "por eso quiero que todas las viudas se casen, que tengan hijos, que sean amas de casa y que no den lugar a las críticas del enemigo" (I Ti. 5, 14), ya que se creía que las viudas jóvenes podrían corromperse sin la tutela de un hombre. La segunda razón era que los viudos, al casarse de nueva cuenta, podían obtener una madre sustituta que atendiera en casa a los hijos huérfanos de madre, mientras que las viudas obtenían un padre para sus hijos huérfanos, así como la protección económica y moral de un marido.

\section{CONCLUSIONES}

Las epidemias fueron un suceso frecuente en las poblaciones del antiguo régimen, que menguaba las poblaciones con altas cifras de muertos. En el caso de Nueva España las principales epidemias se debieron primordialmente a tres enfermedades: viruela, sarampión y fiebres o matlazáhuatl. Las epidemias de 1737-1738 y de 1813-1814 fueron dos de las más relevantes por la alta cantidad de muertos que provocaron y por tener una alta intensidad, de acuerdo con el factor multiplicador (o número de veces que se multiplican las muertes con respecto del promedio de los dos años anteriores sin epidemia), que se empleó en este estudio para medirlas. La de matlazáhuatl de 1737-1738 fue la de mayor intensidad de todo el periodo colonial y la de 1813-1814 fue la tercera más fuerte, sólo detrás de la viruela de 1780.

Las epidemias de tifo afectaban predominantemente a la población adulta y sus consecuencias fueron más radicales, en tanto que desarticulaban casi por completo a las familias con la muerte del padre, de la madre o de ambos. Ante la muerte de los padres y, en general de los adultos, las familias se veían afectadas al perderse el sostén económico de los integrantes en edad de producir o lograr el sustento a los miembros más vulnerables. Ante esto, los huérfanos posiblemente debían salir a ganarse la vida mendigando o, en el mejor de los casos, eran recogidos por sus familiares y posteriormente se

${ }_{14}$ Murillo (2004, libro IV, título xxi: de las segundas nupcias).

${ }^{15}$ En la visita pastoral hecha por el obispo de Michoacán, fray Marcos Ramírez de Prado, hacia 1656, en Taximaroa compelía a las viudas y viudos a casarse en un plazo de dos meses. Dicha visita se encuentra en Fondo Parroquial. Sección Sacramentos. Serie Casamientos. Subserie Libro de casamientos de españoles (1646-1683), fs. 10-15, caja 21. АнРSJHM, México. 
contrataban como aprendices o ayudantes, e incluso como "arrimados" en las haciendas y otros centros de trabajo. Sin embargo, sobre este tema es necesario abundar con más casos sobre la afectación de las epidemias en la estructura familiar, al igual que documentar con datos concretos las estrategias de supervivencia de los huérfanos.

A través del estudio demográfico del caso de Taximaroa, una parroquia del obispado de Michoacán, durante dos epidemias (la del matlazáhuatl de 1737-1738 y las fiebres de 1713-1814) se demuestra cómo estos sucesos llevaban a la tumba a familias completas o, en el mejor de los casos, las mutilaba provocando otros fenómenos como la búsqueda de las segundas nupcias. Gracias al método de reconstitución de familias se puede indagar un poco más respecto de las consecuencias de las epidemias en los grupos familiares y los trastornos que sufrían comúnmente durante o después de una sobremortalidad. Ante la omnipresencia de la muerte en el entorno familiar, el viudo o la viuda preferían las siguientes nupcias antes que el luto a la pareja fallecida, ya que volverse a casar era una estrategia de supervivencia misma.

\section{LISTA DE REFERENCIAS}

Aguilera Núñez, A. R. (2011). La población de Teitipac: ensayo de reconstrucción de familias y dinámica demográfica de antiguo régimen, 1730-1820 (Tesis de maestría inédita). Universidad Autónoma del Estado de México, México.

Aguilera Núñez, A. R. (2013). Difusión e incidencia comparada por grupo de edad y localidad. Epidemia de matlazáhuatl, parroquia de Toluca, 1737. En M. A. Magaña Mancillas (coord.), Epidemias y rutas de propagación en la Nueva España y México (siglos XVIII-XIX) (pp. 33-59). Mexicali: Universidad Autónoma de Baja California. Aguilera Núñez, A. R. (2017). El valle de Tlacolula, Oaxaca, bajo los efectos de la epidemia de matlazáhuatl, 1738-1739. En J. G. González Flores (coord.), Epidemias de matlazáhuatl, tabardillo y tifo en Nueva España y México. Sobremortalidades con incidencia en la población adulta del siglo XVII al XIX (pp. 65-85). Saltillo: Universidad Autónoma de Coahuila.

Arenas Hernández, T. D. (2014). Migración a corta distancia. La población de la parroquia de Sombrerete (1677-1825). Zacatecas: Universidad Autónoma de Zacatecas/El Colegio de Michoacán.

Becerra Jiménez, C. (2017). Las fiebres de 1814 y la viruela de 1815. Dos años de sobremortalidad en los Altos de Jalisco. En J. G. González Flores (coord.), Epidemias de 
matlazáhuatl, tabardillo y tifo en Nueva España y México. Sobremortalidades con incidencia en la población adulta del siglo XVII al XIX (pp. 176-195). Saltillo: Universidad Autónoma de Coahuila.

Biblia Latinoamericana (2005). Madrid: San Pablo, Verbo Divino.

Cabrera y Quintero, C. (1981). Escudo de Armas de México. México: IMss.

Calvo, T. (1973). Acatzingo. México: Instituto Nacional de Antropología e Historia.

Canales Guerrero, P. (2006). Propuesta metodológica y estudio de caso. ¿Crisis alimentarias o crisis epidémicas? Tendencia demográfica y mortalidad diferencial, Zinacantepec 1613-1816. En A. Molina del Villar y D. Navarrete Gómez (coords.), Problemas demográficos vistos desde la historia. Poblamiento y tendencias demográficas, siglos XVI al XVIII (pp. 67-116). Zamora: El Colegio de Michoacán/ciesAs.

Canales Guerrero, P. (2017). Historia natural del tifo epidémico: comprender la alta incidencia y la rapidez en la transmisión de la Rickettsia prowaseckii. En J. G. González Flores (coord.), Epidemias de matlazáhuatl, tabardillo y tifo en Nueva España y México. Sobremortalidades con incidencia en la población adulta del siglo XVII al XIX (pp. 11-23). Saltillo: Universidad Autónoma de Coahuila.

Carbajal López, D. (2008). La población en Bolaños 1740-1848 Dinámica demográfica, familia y mestizaje. Zamora: El Colegio de Michoacán.

Castañeda, C. (2006). Los caminos de México a Guadalajara. En C. Cramaussel (ed.), Rutas de la Nueva España (pp. 263-274). Zamora: El Colegio de Michoacán.

Castillo Palma, N. A., Vázquez Mendoza, N., Galicia Orozco, M., Navarro González, A. (2017). El matlazáhuatl, tifo y otras sobremortalidades en Huexotla: adultos y párvulos (1605-1737). En J. G. González Flores (coord.), Epidemias de matlazáhuatl, tabardillo y tifo en Nueva España y México. Sobremortalidades con incidencia en la población adulta del siglo XVII al XIX (pp. 24-36). Saltillo: Universidad Autónoma de Coahuila.

Cramaussel, C. (2006). Poblar la frontera. La provincia de Santa Bárbara en la Nueva Vizcaya durante los siglos XVI y XVII. Zamora: El Colegio de Michoacán.

Cramaussel, C. (2017). El matlazáhuatl y el tifo en el norte de la Nueva Vizcaya (17381815). En J. G. González Flores (coord.), Epidemias de matlazáhuatl, tabardillo y tifo en Nueva España y México. Sobremortalidades con incidencia en la población adulta del siglo XVII al XIX (pp. 86-102). Saltillo: Universidad Autónoma de Coahuila.

Cuenya Mateos, M. A. (1999). Puebla de los Ángeles en tiempos de una peste colonial. Zamora: El Colegio de Michoacán/Benemérita Universidad Autónoma de Puebla.

Flores Gutiérrez, V. (2017). Incidencia, espacio temporal de la epidemia de tifo de 1737. Zinacantepec, Valle de Toluca. En J. G. González Flores (coord.), Epidemias de matlazáhuatl, tabardillo y tifo en Nueva España y México. Sobremortalidades con in- 
cidencia en la población adulta del siglo XVII al XIX (pp. 54-64). Saltillo: Universidad Autónoma de Coahuila.

González Flores, J. G. (2013). Consecuencias demográficas y rutas de propagación de las epidemias en Taximaroa (1738-1798). En M. A. Magaña Mancillas (coord.), Epidemias y rutas de propagación en la Nueva España y México (siglos XVIII-XIX) (pp. 147-177). Mexicali: Universidad Autónoma de Baja California.

González Flores, J. G. (2016). Mestizaje de papel. Dinámica demográfica y familias de calidad múltiple en Taximaroa (1667-1826). Zamora: El Colegio de Michoacán/Universidad Autónoma de Coahuila.

González Flores, J. G. (2017). La epidemia de fiebres epidémicas o tifo en 1814 en Parras. En J. G. González Flores (coord.), Epidemias de matlazáhuatl, tabardillo y tifo en Nueva España y México. Sobremortalidades con incidencia en la población adulta del siglo XVII al XIX (pp. 214-225). Saltillo: Universidad Autónoma de Coahuila.

Henry, L. (1983). Manual de demografía histórica. Barcelona: Editorial Crítica.

Malvido, E. y Peniche, P. (2013). Los huérfanos del cólera morbus en Yucatán, 1833. Historia Mexicana, LXIII(1), 111-170.

Márquez Morfín, L. (1994) Desigualdad ante la muerte en la Ciudad de México: El tifo y el cólera. México: Siglo XXI.

Molina del Villar, A. (2001). La Nueva España y el Matlazáhuatl, 1736-1739. México: CIESAs/El Colegio de Michoacán.

Montaña, L. (1817). Sobre el matlazáhuatl, o calentura epidémica manchada que pasa a ser peste y que es frecuente en esta N. E. con un modo sencillo y fácil de socorrer a los enfermos donde no haya médicos que le asistan, y cuya eficacia y seguridad se experimentó el año de 1813. México: Imprenta de don Mariano de Zúñiga y Ontiveros.

Morin, C. (1973). Santa Inés Zacatelco, 1646-1815: contribución a la demografía histórica del México colonial. México: Instituto Nacional de Antropología e Historia.

Murillo Velarde S. J., P. (2004). Curso de derecho canónico hispano e indiano (libro IV, título xxi: de las segundas nupcias). A. Carrillo Cazares (coord.). Michoacán: El Colegio d e Michoacán, [CD-ROM].

Ortiz Escamilla, J. (1994). Insurgencia y seguridad pública en la Ciudad de México, 1810-1815. En R. Hernández Franyuti (coord.), La ciudad de México durante la primera mitad del siglo XIX (vol. 2: Gobierno y política/Sociedad y cultura). México: Instituto de Investigaciones Dr. José María Luis Mora.

Pérez Escutia, R. A. (1986). Taximaroa. Historia de un pueblo michoacano, Morelia: Gobierno del Estado de Michoacán.

Pérez Escutia, R. A. (1990). Historia de Maravatío, Michoacán. Maravatío: Comité Organizador de los Festejos del 450 Aniversario de Maravatío. 
Rabell Romero, C. (1990). La población novohispana a la luz de los registros parroquiales, México: Instituto de Investigaciones Históricas-Universidad Nacional Autónoma de México.

Severo Sánchez, J. J. (2013). El tifo, epidemia y endemia en Metepec en el primer tercio del siglo xıx: rutas de propagación y mortalidad diferencial. En M. A. Magaña Mancillas (coord.), Epidemias y rutas de propagación en la Nueva España y México (siglos XVIII -XIX) (pp. 59-115). Mexicali: Universidad Autónoma de Baja California.

Talavera Ibarra, O. U. (2007). La transformación de Uruapan en la época colonial. Demografía y sociedad: segunda mitad del siglo XVII y siglo XVIII. México: Universidad Autónoma Metropolitana.

Talavera Ibarra, O. U. (2013). Las epidemias, el hambre y la guerra en Valladolid y Uruapan durante el periodo borbónico. En M. A. Magaña Mancillas (coord.), Epidemias y rutas de propagación en la Nueva España y México (siglos XVIII-XIX) (pp. 116-146). Mexicali: Universidad Autónoma de Baja California.

Talavera Ibarra, O. U. (2017). El tifo y la crisis de mortalidad de adultos en Valladolid, Pátzcuaro y Uruapan. En J. G. González Flores (coord.), Epidemias de matlazáhuatl, tabardillo y tifo en Nueva España y México. Sobremortalidades con incidencia en la población adulta del siglo XVII al XIX (pp. 37-53). Saltillo: Universidad Autónoma de Coahuila.

Torres Franco, C. P. (2013). Epidemias y segundas nupcias en la villa de la Encarnación. En M. A. Magaña Mancillas (coord.), Epidemias y rutas de propagación en la Nueva España y México (siglos XVIII-XIX) (pp. 211-239). Mexicali: Universidad Autónoma de Baja California.

Torres Franco, C. P. (2017a). ¿Entre parientes? Demografía, estrategias matrimoniales y reconstrucción de familias en la parroquia de Encarnación, 1778-1822. Zamora: El Colegio de Michoacán.

Torres Franco, C. P. (2017b). La sobremortalidad de 1814-1817 y su impacto en las familias de Encarnación. En J. G. González Flores (coord.), Epidemias de matlazáhuatl, tabardillo y tifo en la Nueva España y México (196-213). Saltillo: Universidad Autónoma de Coahuila. 


\section{OTRAS FUENTES}

\section{Archivo}

AhPsjнm Archivo Histórico de la Parroquia de San José, Hidalgo, Michoacán, México. 